\title{
Enhancing business community disaster resilience. A structuredliterature review of the role of dynamic capabilities
}

\author{
This is an Author Accepted Manuscript published in Continuity \& Resilience Review
}

\begin{abstract}
Purpose - The purpose of the current literature reviews to contribute to the study of organisational resilience. The study intends to understand the role of dynamic capability flow in creating more resilient business communities. The study tries to relate to how continuous learning enables business communities to plan for, respond to and bounce back from disasters.

Design/methodology/approach - A structured literature review of 38 empirical studies indicates organisational resilience and highlights the dynamic attributes of organisational resilience and the importance of knowledge interactions and information sharing.

Findings - Continuous learning results in complex dynamic capability manifested through research and innovations, technological implementations, social learnings and community knowledge sharing. This clearly emphasises the role of dynamic capabilities in fostering disaster resilience in organisations and business communities.

Research limitations/implications - Research limitations on continuous learning can be cited as to incorporate case study methods related to organisational experiences during the COVID-19 pandemic while also reviewing digital knowledge transfer strategies and influencing factors.

Practical implications - The study for fostering resilience in the business ecosystem needs to be embedded in the continuous learning process, and it also includes knowledge sharing and collaboration, both externally and internally, for the business community.

Social implications - Social implications for this study relate to the seamless flow of the knowledge transfer and knowledge sharing process. The dynamic process of organisational and the business community resilience is a key outcome of this knowledge sharing and knowledge transfer process.

Originality/value - A conceptual framework was developed from the review, emphasising how dynamic capabilities through continuous learning enhance business community resilience.
\end{abstract}

Keywords Continuous learning, Learning, Knowledge, Disaster resilience, Community resilience, Social resilience

\section{Introduction}

Disaster happens and is becoming more common; it can be due to unexpected natural events such as global epidemic or hazards from climate changes and poses a risk to health and wellbeing (Lavell et al., 2012). Disasters can also be due to global financial and economic distress resulting from events external to an organisation or national economies such as economic crisis or political changes (McGuinness et al., 2018). Disasters can also be internal to an organisation, such as business failures and systemic risk with a cumulating effect on the business community and national economies (Helbing, 2013). With disasters having devastating effects on individual wellbeing, business communities and national economies, there is a need to improve disaster management's effectiveness and efficiency worldwide. However, business communities and national economies should be more proactive in disasters, anticipate and plan for these challenges and leverage potential opportunities.

Lee et al. (2013) argued that if organisations are not prepared to respond to disaster events, it will affect the business communities and national economies. However, the size of an 
organisation and national economies can determine their response to these unexpected events (Linnenluecke, 2017; Sutcliffe and Vogus, 2003). Weick and Sutcliffe (2015) argued that larger organisations, unlike smaller ones, leverage their higher level of financial resources to anticipate, plan and adjust to reduce these unexpected events. However, lack of coordination, lack of access to training, experience, inadequate infrastructures and the development of specialised knowledge are other factors that influence organisational responses to these unexpected events (Petrudi et al., 2020).

\section{Organisational resilience}

Resilience is defined as the capacity to cope with an unexpected danger or event and learning to recover after this event has become manifest (Wildavsky, 1991). It is an attribute that enables individuals and organisations to cope and thrive during a period of disaster or financial uncertainties (Conz and Magnani, 2020). Resilience is, therefore, the ability, capability or capacity to plan for, react to and recover from disaster events or financial risks and uncertainties opportunities. These factors, namely the ability to anticipate, monitor, respond, recover and learn from disaster events, contribute to an organisation's performance during these events (Hollnagel, 2014). Therefore, organisations must develop resilience by being agile and adapt positively to the economic activities affected by disaster events and financial fluctuations to improve performances.

Organisational resilience is the organisation's ability to anticipate, prepare for, respond to and adapt to sudden disaster and financial disruptions (Denver, 2017). Pal et al. (2014) related resilience to organisational performance and argued that it is the capability to plan for disruptive events and financial uncertainties to sustain superior organisational performance. Some researchers referred to resilience as an organisational ability to withstand and adjust to these disruptive events in the business environment (Acquaah et al., 2011). Other studies associated resilience with reactive capabilities after a disruption (Kamalahmadi and Parast, 2016). However, Bouaziz and Hachicha (2018) argued that resilience is more than resistance or adaptation to change. They explained that it involves adopting a proactive attitude, anticipating and leveraging on change. Therefore, organisational resilience is the organisation's ability to anticipate, withstand, respond to and recover from natural disasters or financial uncertainties that can undermine organisational stabilities (Annarelli and Nonino, 2016; DesJardine et al., 2019; Duchek et al., 2020).

Therefore, the authors build upon Conz and Magnani (2020) study that highlights the different resilience definitions in the business and management research area and elaborates a conceptual framework that defines an organisation's resilience as a process in time. Conz and Magnani (2020) argued that different organisational capabilities are required at various disaster stages, and organisation must possess these resiliences before, during and after these unexpected events. However, Williams et al. (2017) explained that organisational resilience evolves, resulting in organisational reactions and responses to the unexpected changes in the business environment while developing alternative plans to recover from these situations. Gilly et al. (2014) further explained that organisations must process the capabilities to anticipate, reduce and adjust their routine activities in response to these external events. In addition to the changes in their routine activities, organisations must also change their abilities and behaviours in anticipating, reacting, responding and recovering from disaster events (Sutcliffe and Vogus, 2003; Buyl et al., 2019). Hamel and Valikangas (2003) argued that organisations must have the resilience to transform, adjust and respond continuously while preserving organisational values, processes and behaviours. The organisational resilience must evolve in time, enabling the organisation to adjust and develop alternative plans of action in response to disaster events (Williams et al., 2017). However, the organisation requires information and knowledge to transform from reactive 
organisational resilience to dynamic or proactive organisational resilience (Williams et al., 2017; Giroux and Prior, 2012).

\section{Organisational resilience before disaster event}

Building on Pal et al. (2014) argument that organisations must possess resilience capability or develop to respond to unexpected disaster events and sustain organisational performance during a disaster event. In external disruptions to organisational processes, Ambulkar et al. (2015) highlighted that organisations must possess the resilience to plan for, adapt to and adequately respond to changes in the business environment. With disaster events and financial uncertainties resulting from internal and external factors impacting organisational performances, organisations must have the resilience to react positively to these conditions. Several researchers have focused on making organisations more resilient through scenariobased training, thereby providing organisations and business communities with information and knowledge to take proactive plans to adjust and succeed during the disaster event (Saurin et al., 2014). To sustain organisational performance, Brewton et al. (2010) and Danes et al. (2009) highlighted the importance of building capabilities through internal and external resources. They argued that organisations must interact and coordinate with the business community to learn and share valuable knowledge and information and develop organisational resources. However, this disaster arrangement must be made in advance to enable appropriate and effective responses to the business environment changes (Kachali et al., 2018). There is a need for effective planning and training for different scenarios and the different threat types facing the business communities. Therefore, organisational resilience must have the resources, capabilities and structure to facilitate the continuous learning and knowledge interactions with the business communities to plan for and adjust to disaster events.

\section{Organisational resilience during disaster events}

Organisational resilience is the ability and capacity to adapt and withstand disaster events or financial uncertainties within the business environment (Starr et al., 2003; Acquaah et al., 2011). Organisational resilience enables an organisation to absorb, sustain and recover from disaster events and their impact on business continuity (Carmeli and Markman, 2011; Dumitraşcu and Dumitraşcu, 2016). The organisation must have the ability to maintain, positively adjust or adapt its essential structure and function during these uncertainties (Biggs et al., 2014; Ismail et al., 2011). The structure allows the organisation to develop resistance to unexpected adverse conditions, adapt, recover and sustain the business during the disaster event (Ates and Bititci, 2011; Moore and Manring, 2009). However, organisations need first to understand the potential impact of the disaster event or financial uncertainties in developing an appropriate response (Lengnick-Hall and Beck, 2005).

Knowledge interaction with business communities enables cooperation and collaboration while developing a community mindset that benefits everyone, including pooling information and resources to help withstand business uncertainties and the capability to adapt to new risk environments and improve recovery times (Burnard and Bhamra, 2011; Wedawatta and Ingirige, 2012). Community resilience is the synergy between the business communities and organisations before, during and aftershocks or stress to ensure a long-term and sustainable future (RAs@nen et al., 2020). The stronger the connections between local businesses and their community, the more communities have proactive and reactive procedures in place, the easier and faster a community and individual business can sense, absorb, adapt and rebound from natural or financial disruptions (Jaaron and Backhouse, 2014; Choudhury et al., 2019). Therefore, organisational resilience enables the organisation and supports the business communities to adapt to a constantly changing business environment or a disaster situation 
to remain competitive (Richtner and L6fsten, 2014; Alonso and Bressan, 2015; Smallbone et al., 2012).

\section{Organisational resilience after disaster events}

In addition to the capability to adapt and resist disaster events, an organisation must develop the capabilities to recover from these events, respond to change, maintain or reconfigure its structure after an event occurred. Organisational resilience is the organisation's ability to respond to crisis or change and maintain its competitive advantage ( $\mathrm{Pal}$ et al., 2014; Smallbone et al., 2012). Su and Linderman (2016) further explained that organisational resilience is the ability to cope with and respond to changes in the business environment. These views provide post-disaster event's organisational capabilities to survive unexpected adverse situations (Linnenluecke and Griffiths, 2010).

Linnenluecke et al. (2012) argue that resilience is an organisational capacity to absorb the impact of and recover from disaster occurrences, while other researchers argued that organisational resilience is about recovering, rebounding and returning to a pre-disturbance (disaster) state (Bhamra et al., 2011; Herbane, 2015; Edgeman and Williams, 2014). However, these views do not provide insight into how to survive, recover, maintain or improve previous organisational performance. Tracey and French (2017) argued that to recover and improve organisational performance after disaster events, organisations must adjust their structure in response to these internal or external threats. Demmer et al. (2011) further explained that organisations need to have the ability to continually evolve, implement rapid decisionmaking processes and adapt routines and strategies to changing conditions to recover and remain competitive.

\section{Dynamic attributes of organisational resilience}

According to Ismail et al. (2011), organisational resilience enables organisations to react, respond and recover while adjusting to changing business environment. Organisational resilience enhanced the ability to adapt, recover, sustain and improve organisational performance during unexpected change events (Dahles and Susilowati, 2015; Tracey and French, 2017).

\section{Purpose}

The previous definitions of organisation resilience focus on organisational proactive and reactive responses to disaster events. These definitions also highlight transformation in organisational actions, behaviour and structures before, during and after an unexpected change in the business environment. Organisations are able to anticipate, cope with, adjust to and engage in transformative actions in response to the sudden change in the business environment (Lengnick-Hall et al., 2011; Rodríguez-Sanchez et al., 2019). However, resilience depends on a social system and the ability to learn from previous experiences to achieve better disaster responses in the future (Jan, 2013). The continuous involvement in sociogovernment interactions and collaboration within the business communities enables an organisation to contribute to its resilience (Biggs et al., 2012; Prayag, 2018). The knowledge interactions and information sharing will enable organisations to assess the internal and external threats situations and adjust their routine in response to the disaster event (Gilly et al., 2014). The knowledge and capabilities developed through these collaborations and interactions enable organisations and business communities to anticipate effectively, respond to and recover from the impacts of uncertainties within the business environment. Therefore, the cooperation and information-sharing within the business communities enable 
organisations or business communities to match their vulnerability to changes in the business environment to reduce the impact.

Several researchers have attempted to discover specific elements, such as resources, organisational structures, human resource practices, designing adaptation strategies or systems that support organisations' resilience (Bhamra et al., 2011; Linnenluecke, 2017; DesJardine et al., 2019). Reinmoeller and Van Baardwijk (2005) further argued that the changes in routines contribute to building organisational resilience and improving organisational competitive advantage. However, access to information and relevant data and stimulating the learning process enables organisations to innovate and adjust their strategies at different stages in response to disaster events.

The purpose of the current literature reviews to contribute to the study of organisational resilience. With disasters posing a risk to individual health and wellbeing while also affecting business communities and national economies, there is a need to improve disaster management's effectiveness and efficiency. The study builds upon previous studies on organisational learning to identify how business communities respond to disaster events and develop resilience. The study attempts to relate from existing literature on how organisational disaster experiences and the continuous learning from these events enable business communities to plan for, respond to and bounce back from disasters. Using the conceptual framework designed to enhance business community disaster, the author intends to understand the role of dynamic capability in creating more resilient business communities.

\section{Methodology}

The inclusion and exclusion criteria The current study is a structured literature review, and the methodology is adopted from Sonet al. (2020). The initial search with the search string "dynamic Capability and disasterresilience and continuous learning and social resilience and community resilience literaturereview" yielded 5,288 Articles. The database used for this search were Science Direct (225articles), Emerald (169 Articles), Business Source Premier $(4,888)$ and Scopus $(4)$. Theconsidered time frame was the last ten years from the year 2010-2021, which resulted in 3,224articles narrowing down the search. The review of the last 11 years was carried out tounderstand how the business communities have adapted, adjusted and recovered afterenduring the disaster shocks, including financial meltdowns and the COVID-19 crisis and its repercussions. Each database was searched to locate the subject of interest (see Figure 1), where the keywords considered.

The search and screening results are as shown above in Figure 1. The articles that pertained to the years from 2010 to 2021 were narrowed down to 52 articles. The process of eliminating the articles was managed in three steps. PRISMA flow chart has been used for a more detailed selection process structure (Moher et al., 2009). The screened articles. Based on the abstract and title, further narrowed down the relevant articles to 296. These eliminated the non-research articles, the non-peer-reviewed articles, non-social science articles and nonbusiness and management articles. These 296 articles were then considered for abstract and a full-text review. The articles that did not have the core subject as disaster resilience, community resilience and social resilience were eliminated. Those that were on general resilience were eliminated as they did relate to fostering resilience in any phases of disaster management: the planning phase, response phase and recovery phase. It culminated into 38 relevant articles. The four stages here are the identification, screening, eligibility and inclusion of the articles.

\section{Emphasis on continuous learning}

In the last section, the selection process of the relevant articles. This section is about the keywords that the articles are based on. Table 1: Table the keywords illustrate the continuous 


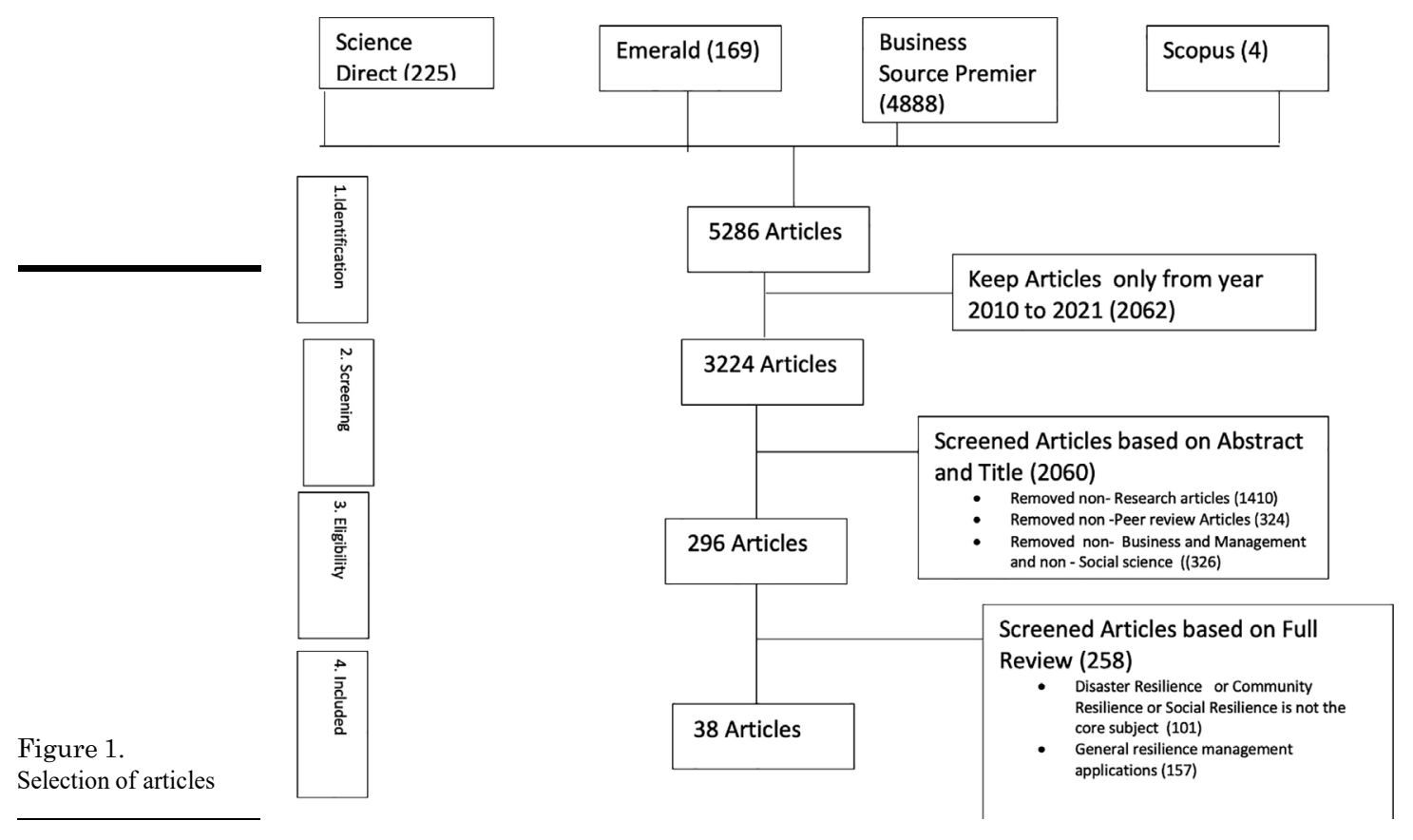

learning/learning/knowledge sharing/knowledge transfer as the key suggestions to foster resilience amongst the community. The keyword pertaining to every article is marked, and the following suggestions are highlighted:

(1) Continuous learning is emphasised for ensuring the scenario planning in the planning phase.

(2) The application of this knowledge and continuous learning in the response phase.

(3) The strategic implementation of continuous learning in the recovery phase.

Continuous learning is the key aspect of overcoming disaster-stricken communities and can be considered enhancing the dynamic capabilities that pertain to the three areas of sensing, scoping and transforming. Enhancing the dynamic capability aspect through the knowledge management that has a continuous trajectory of changing path emphasises its importance. Table 1 demonstrates the importance of continuous learning for those studies that have dealt with community resilience, social resilience and disaster resilience.

In the last section, the emphasis on continuous learning is demonstrated by each article. In this section, the articles have been analysed as per their year of publication. It is seen in Figure 2 that 2020 has seen the highest number of articles published that suggests a direction to bounce back from this COVID-19 pandemic. Continuous learning, learning, knowledge sharing and knowledge transfers are the most conspicuous suggestions shared by these articles (see Figure 3).

In Figure 2, the keyword analysis demonstrates that the highest number of articles reflect on the process of continuous learning. The other aspect of learning is associated with disaster resilience, social resilience and community resilience. The COVID-19 phase had been a very challenging time for the business community. These articles highlighted the resilience path 


\begin{tabular}{|c|c|c|c|c|}
\hline Name of articles & $\begin{array}{l}\text { Continuous } \\
\text { learning/learning/ } \\
\text { knowledge }\end{array}$ & $\begin{array}{l}\text { Disaster } \\
\text { resilience }\end{array}$ & $\begin{array}{l}\text { Community } \\
\text { resilience }\end{array}$ & $\begin{array}{l}\text { Social } \\
\text { resilience }\end{array}$ \\
\hline $\begin{array}{l}\text { Review of finance and investment in } \\
\text { disaster resilience in the built } \\
\text { environment (Adeniyi et al., 2016) }\end{array}$ & & Yes & & \\
\hline $\begin{array}{l}\text { Social capital and community resilience } \\
\text { (Aldrich and Meyer, 2015) }\end{array}$ & & & Yes & \\
\hline $\begin{array}{l}\text { Disaster management digitally } \\
\text { transformed: Exploring the impact and } \\
\text { key determinants from the UK national } \\
\text { disaster management experience } \\
\text { (AlHinai, 2020) }\end{array}$ & Yes & Yes & & \\
\hline $\begin{array}{l}\text { Agility and resilience as antecedents of } \\
\text { supply chain performance under } \\
\text { moderating effects of organisational } \\
\text { culture within the humanitarian setting: } \\
\text { a dynamic capability view (Altay et al., } \\
\text { 2018) }\end{array}$ & Yes & Yes & & \\
\hline $\begin{array}{l}\text { Supply chain readiness, response and } \\
\text { recovery for resilience (Chowdhury et al., } \\
\text { 2016) }\end{array}$ & Yes & & & \\
\hline $\begin{array}{l}\text { Measuring social resilience: trade-offs, } \\
\text { challenges and opportunities for } \\
\text { indicator models in transforming } \\
\text { societies (Copeland } \text { et al., 2020) }\end{array}$ & Yes & & Yes & \\
\hline $\begin{array}{l}\text { Measuring the Disaster Resilience of an } \\
\text { Urban Community Using ANP-FCE }\end{array}$ & & Yes & Yes & \\
\hline $\begin{array}{l}\text { Method from the Perspective of Capitals } \\
\text { (Cui and Li, 2019) }\end{array}$ & & & & \\
\hline $\begin{array}{l}\text { Supply network resilience: a systematic } \\
\text { literature review and future research } \\
\text { (Datta, 2017) }\end{array}$ & & & & \\
\hline $\begin{array}{l}\text { Disaster City Digital Twin: a vision for } \\
\text { integrating artificial and human } \\
\text { intelligence for disaster management } \\
\text { (Fan et al., 2021) }\end{array}$ & Yes & & & \\
\hline $\begin{array}{l}\text { Harnessing informal education for } \\
\text { community resilience (Feng et al., 2018) }\end{array}$ & Yes & Yes & & \\
\hline $\begin{array}{l}\text { Infrastructure resilience assessment, } \\
\text { management and governance- - state and } \\
\text { perspectives (Heinimann and Hatfield, } \\
\text { 2017) }\end{array}$ & Yes & Yes & Yes & \\
\hline $\begin{array}{l}\text { The effect of social media on the } \\
\text { dynamics of (self) resilience during } \\
\text { disasters: a literature review (Jurgens } \\
\text { and Helsloot, 2018) }\end{array}$ & & Yes & & \\
\hline $\begin{array}{l}\text { Resilience performance scorecard: } \\
\text { measuring urban disaster resilience at }\end{array}$ & Yes & Yes & & Yes \\
\hline
\end{tabular}
multiple levels of geography with case study application to Lalitpur, Nepal (Khazai et al., 2018)

Implementing capacity development for disaster risk reduction as a social learning system (Kong et al., 2020)

Table 1.

(continued) Table of the keywords 


\begin{tabular}{|c|c|c|c|c|}
\hline Name of articles & $\begin{array}{l}\text { Continuous } \\
\text { learning/learning/ } \\
\text { knowledge }\end{array}$ & $\begin{array}{l}\text { Disaster } \\
\text { resilience }\end{array}$ & $\begin{array}{l}\text { Community } \\
\text { resilience }\end{array}$ & $\begin{array}{l}\text { Social } \\
\text { resilience }\end{array}$ \\
\hline $\begin{array}{l}\text { Post-disaster tourism: building resilience } \\
\text { through community-led approaches in } \\
\text { the aftermath of the } 2011 \text { disasters in } \\
\text { Japan (Lin et al., 2018) } \\
\text { organisational resilience (Ma et al., 2018) }\end{array}$ & Yes & Yes & Yes & \\
\hline $\begin{array}{l}\text { A collaboration-resilience framework for } \\
\text { disaster management supply networks: a } \\
\text { case study of the Philippines (Medel } \text { et al., } \\
\text { 2020) }\end{array}$ & & Yes & & \\
\hline $\begin{array}{l}\text { Towards developing a model for the } \\
\text { evaluation of hospital disaster resilience: } \\
\text { a systematic review preprint } \\
\text { (Ostadtaghizadeh } \text { et al., 2019) }\end{array}$ & Yes & & & \\
\hline $\begin{array}{l}\text { Top-down assessment of disaster } \\
\text { resilience: a conceptual framework using } \\
\text { coping and adaptive capacities (Parsons } \\
\text { et al., 2016) }\end{array}$ & Yes & Yes & & Yes \\
\hline $\begin{array}{l}\text { Preparedness and community resilience } \\
\text { in disaster-prone areas: cross-sectoral } \\
\text { collaborations in South Louisiana, } 2018 \\
\text { (Pollock et al., 2019) }\end{array}$ & Yes & Yes & Yes & \\
\hline $\begin{array}{l}\text { Rome was not built in a day. Resilience } \\
\text { and the eternal city: insights for urban } \\
\text { management (Simone et al., 2021) }\end{array}$ & Yes & & & Yes \\
\hline $\begin{array}{l}\text { Learning from disaster: community- } \\
\text { based marine protected areas in Fiji } \\
\text { (Takasaki, 2016) }\end{array}$ & Yes & & Yes & \\
\hline
\end{tabular}

Figure 2.

Year-wise count of articles

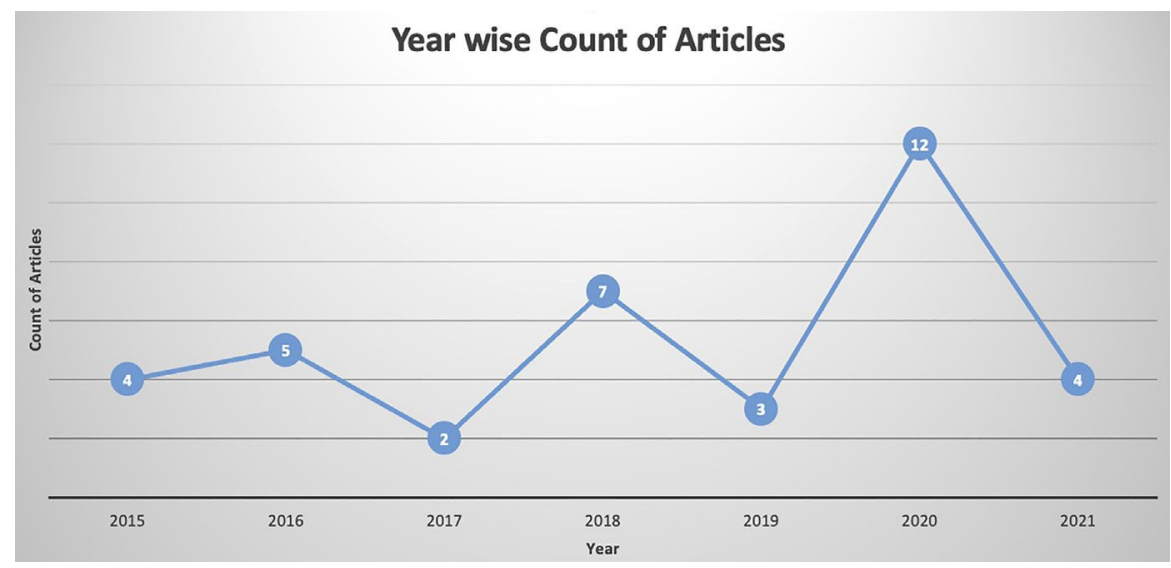

as enhancing the dynamic capabilities through continuous learning. This continuous learning can help in the three areas related to dynamic capabilities. The three areas in which continuous learning can be applied are during the disaster planning phase, called the sensing 


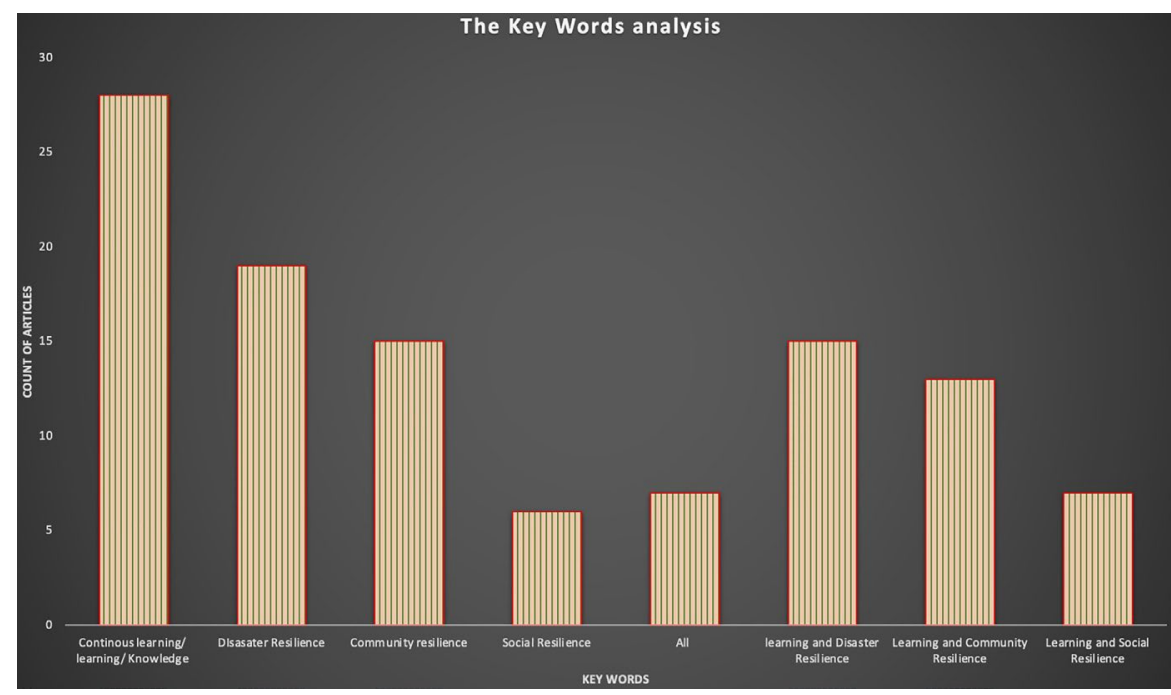

Figure 3. The keyword analysis

scope for the dynamic capabilities to be implemented. The past learnings can be utilised to prepare the scenario planning established in the disaster planning phase. This continuous learning in the form of group and clusters learning across the employees can also be at an aggregated organisational leadership level. It can also happen through co-creation and knowledge exchange of the same industries in the economy (Bhaskara and Filimonau, 2021). The training from the lessons learnt from past scenarios, promoting research and the related study can contribute to a well prepared and resilient business organisation (Fallah-Aliabadi et al., 2020).

Moreover, antifragility learning has been a concept that flows into the portfolio of capabilities to enhance resilience (Ramezani and Camerani-Matos, 2020). The learning through feedback and adaptive approaches renders a pathway for further improvement (Finucane et al., 2020). Practising networking and lobbying skills can enhance community resilience (Dharmasena et al., 2020). The innovation aspect expands knowledge sharing and flexibility, internal to the firm (Sabahi and Parast, 2020). The flexibility has been highlighted again as an element to adapt to the changing environment and a key element that can make the organisations more resilient (Karman, 2020).

From all these articles, it is evident that 2020 having experienced the very strained and challenging times, have worked more on enhancing the dynamic capabilities in the form of continuous learning, knowledge sharing, training, feedback, adaptive approaches, innovations and research that lead to more agile and resilient organisations.

The keyword analysis graph shows that during the last 11 years, from 2010 to 2021, the most researched area to make organisations more resilient has been continuous learning, knowledge and learning. It is observed that the keyword continuous learning, learning and knowledge sharing has been the suggestion of more than 26 articles. Around 15 articles have cohesively demonstrated that learning is considered one of the key elements of disaster resilience. Further, another 14 articles emphasise learning as a pathway to community resilience, and another seven articles have cited the importance of learning to enable social resilience and recover quickly from the disaster.

From the methodology, the conceptual framework for this research has been derived (see Figure 4). The figure explains how continuous learning within an organisation has been an 
Figure 4.

The conceptual framework

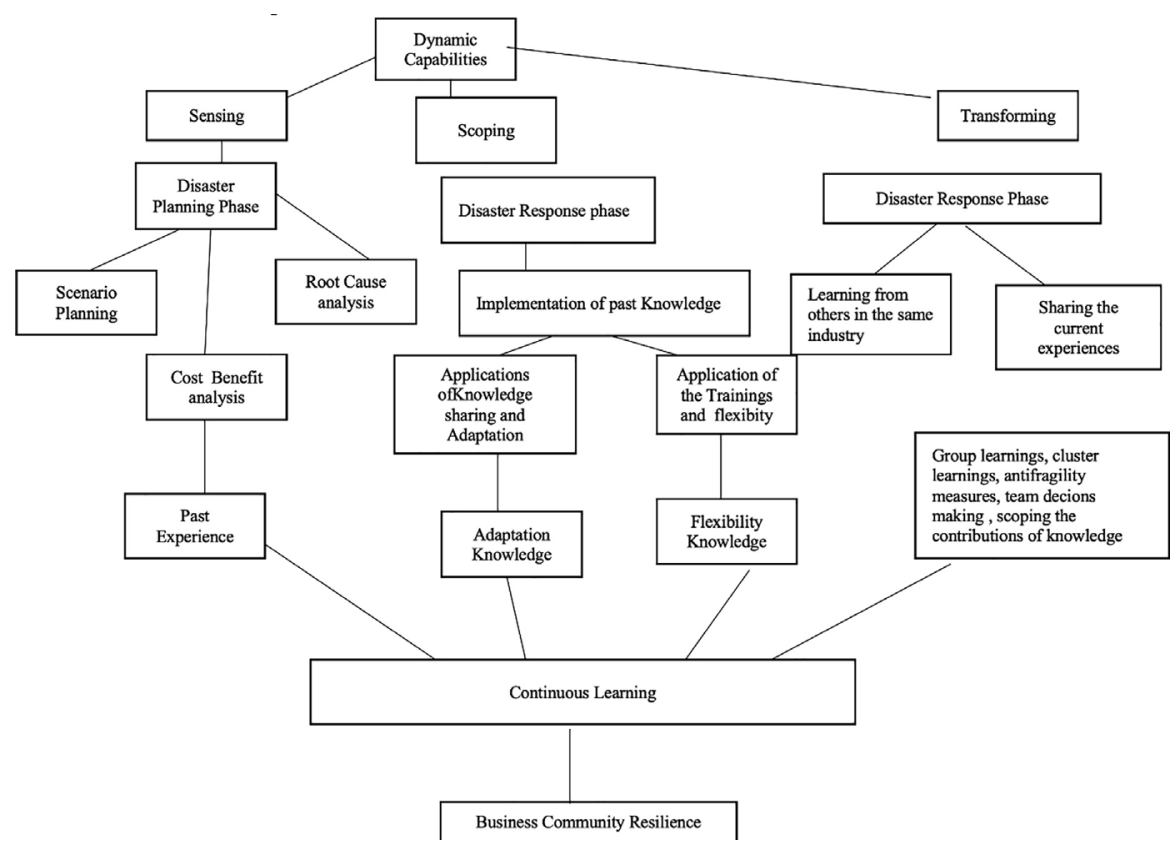

ongoing process in all three phases of disaster management. In the first phase, the authors observed that sensing of dynamic capabilities is used to manage the business communities' disaster resilience. This includes planning, learning from the previous experience, costbenefit analysis and the root cause analysis to create the platform for continuous learning within the organisation and the business community. The second area of the dynamic capability involves scoping contributions to organisational flexibility and adaptability through continuous learning. The agility and adaptability through the robust knowledge base can be a game-changer and make the business community thrive in any difficult situations. The third area for the dynamic capability focuses on organisational transformation through knowledge management processes within and external to the industry. Therefore, continuous learning forms the basis for all three phases, making robust and resilient organisations and business community.

\section{Findings and discussion}

Dynamic capability in the form of continuous learning and disaster resilience

The structured literature review clearly shows the connection between knowledge management and fostering disaster resilience in community creation. The three important areas of the dynamic capabilities: sensing, scoping and transforming, can be considered with this knowledge management. Both internally and externally, the organisations for a business community can create a knowledge management base that can be nurtured and developed over time. Internally the learnings cited are through social learnings like team decision making, collective sensemaking, attitude towards wisdom, respectful interaction, coordination and interaction, group learning, awareness and advocacy. Externally the business community tries to nurture collaboration, research, innovation and incorporating adaptive capabilities from the same industries of the economy. 
The three phases of the disaster: preparedness and planning, response and recovery are all dependent on this continuous learning. The planning and preparedness depend on the sensing aspect of the dynamic capability. The sensing aspect helps to discover the areas that require attention. The very simple case studies on COVID-19 show that the non-human interaction is a perspective that is backed by technology like IoT, AI and blockchain that is the backbone of industry 4.0. The sensing of the evolving technologies and their implementations can be a product of the past knowledge scenarios. The previous experience and challenges can be used to sense the technological progress in those areas based on continuous learning capabilities.

Dynamic capability in the form of continuous learning and community resilience The scoping aspect of the dynamic capabilities is explicitly nurtured through this knowledge management in the organisations. It has been extensively used in the COVID-19 perspective. Taking the organisations to a digital level and creating a virtual environment for the workplace have benefitted the business communities from safely working from home without any major disruptions. A positive correlation is observed between the scoping and implementation of the knowledge base to be agile and flexible and adapt to the most evolved technologies and save businesses and business communities from collapsing. The antifragility in the business ecosystems has ensured the contributions of the multiple areas of knowledge areas. This learning has widened the scoping perspectives and rendered group learnings and cluster learnings successful. Community resilience can be effective in the response phase of the disaster phases. The response phase focuses on adaptability to the changing environment in a very short period. The faster the response turns around, the higher the saving of precious resources like time, money and resources. The antifragility focuses on this response phase, and all the multi-dimensional learnings help create a community that is disaster insulated in a broad sense.

\section{Dynamic capability in the form of continuous learning and social resilience}

This paper's last observation is about transforming the knowledge base into a multidimensional element for a quick recovery for the business communities. Social resilience and change management become part of the recovery process. Knowledge management flows into transforming the social domain. The education policy, training and preparing human resources with adequate skills help society more resilient.

\section{Conclusion}

From our conceptual framework, it is evident that the knowledge created from continuous learning ensures that it is applicable in all three phases of the disaster management process. Through continuous learning, the three phases of planning, response and recovery utilise knowledge to make the organisation and the business community more resilient to adapt, adjust, react and recover from disaster events. As we cannot predict the disasters that can create havoc in our fast-changing lives, it is advised to prepare ourselves for the different kinds of scenarios through our previous experiences.

The study for fostering resilience in the business ecosystem needs to be embedded in the continuous learning process, and it also includes knowledge sharing and collaboration, both externally and internally, for the business community. Continuous learning results in complex dynamic capability manifested through research and innovations, technological implementations, social learnings and community knowledge sharing. This clearly emphasises the role of dynamic capabilities in fostering disaster resilience in organisations and business communities. However, more research on continuous learning can be done to incorporate case study methods related to organisational experiences during the COVID-19 
pandemic while also reviewing digital knowledge transfer strategies and influencing factors. In addition, the conceptual framework to enhance business resilience can be used to investigate the impact of disaster events on the upstream and downstream and how dynamic capabilities through continuous learning contribute to reducing supply chain bottlenecks. The application of dynamic capabilities to understand the efficient use of the organisational resources can be applied to enhance continuous learning within and between business communities to improve organisational resilience.

\section{References}

Acquaah, M., Amoako-Gyampah, K. and Jayaram, J. (2011), "Resilience in family and nonfamily firms: an examination of the relationships between manufacturing strategy, competitive strategy and firm performance", International Journal of Production Research, Vol. 49 No. 18, pp. 5527-5544.

Adeniyi, O., Perera, S. and Collins, A. (2016), "Review of finance and investment in disaster resilience in the built environment", International Journal of Strategic Property Management, Vol. 20 No. 3, pp. 224-238.

Aldrich, D.P. and Meyer, M.A. (2015), "Social capital and community resilience", American Behavioral Scientist, Vol. 59 No. 2, pp. 254-269.

AlHinai, Y.S. (2020), "Disaster management digitally transformed: exploring the impact and key determinants from the UK national disaster management experience", International Journal of Disaster Risk Reduction, Vol. 51, p. 101851.

Alonso, A.D. and Bressan, A. (2015), "Resilience in the context of Italian micro and small wineries: an empirical study", International Journal of Wine Business Research.

Altay, N., Gunasekaran, A., Dubey, R. and Childe, S.J. (2018), "Agility and resilience as antecedents of supply chain performance under moderating effects of organisational culture within the humanitarian setting: a dynamic capability view", Production Planning and Control, Vol. 29 No. 14, pp. 1158-1174.

Ambulkar, S., Blackhurst, J. and Grawe, S. (2015), "Firm's resilience to supply chain disruptions: scale development and empirical examination", Journal of Operations Management, Vol. 33, pp. 111-122.

Annarelli, A. and Nonino, F. (2016), "Strategic and operational management of organisational resilience: current state of research and future directions", Omega, Vol. 62, pp. 1-18.

Ates, A. and Bititci, U. (2011), "Change process: a key enabler for building resilient SMEs", International Journal of Production Research, Vol. 49 No. 18, pp. 5601-5618.

Bhamra, R., Dani, S. and Burnard, K. (2011), "Resilience: the concept, a literature review and future directions", International Journal of Production Research, Vol. 49 No. 18, pp. 5375-5393.

Bhaskara, G.I. and Filimonau, V. (2021), "The COVID-19 pandemic and organisational learning for disaster planning and management: a perspective of tourism businesses from a destination prone to consecutive disasters", Journal of Hospitality and Tourism Management, Vol. 46, pp. 364-375.

Biggs, D., Hall, C.M. and Stoeckl, N. (2012), "The resilience of formal and informal tourism enterprises to disasters: reef tourism in Phuket, Thailand", Journal of Sustainable Tourism, Vol. 20 No. 5, pp. 645-665.

Biggs, D., Swemmer, L., Phillips, G., Stevens, J., Freitag, S. and Grant, R. (2014), "The development of a tourism research framework by South African National Parks to inform management", Koedoe, Vol. 56 No. 2, pp. 1-9.

Bouaziz, F. and Hachicha, Z.S. (2018), "Strategic human resource management practices and organisational resilience", Journal of Management Development.

Brewton, K.E., Danes, S.M., Stafford, K. and Haynes, G.W. (2010), "Determinants of rural and urban family firm resilience", Journal of Family Business Strategy, Vol. 1 No. 3, pp. 155-166. 
Burnard, K. and Bhamra, R. (2011), "Organisational resilience: development of a conceptual framework for organisational responses", International Journal of Production Research, Vol. 49 No. 18 , pp. 5581-5599.

Buyl, T., Boone, C. and Wade, J.B. (2019), "CEO narcissism, risk-taking, and resilience: an empirical analysis in US commercial banks", Journal of Management, Vol. 45 No. 4, pp. 1372-1400.

Carmeli, A. and Markman, G.D. (2011), "Capture, governance, and resilience: strategy implications from the history of Rome", Strategic Management Journal, Vol. 32 No. 3, pp. 322-341.

Choudhury, M.U.I., Uddin, M.S. and Haque, C.E. (2019), "Nature brings us extreme events, some people cause us prolonged sufferings: the role of good governance in building community resilience to natural disasters in Bangladesh", Journal of Environmental Planning and Management, Vol. 62 No. 10, pp. 1761-1781.

Chowdhury, M.M.H. and Quaddus, M. (2016), "Supply chain readiness, response and recovery for resilience", Supply Chain Management: An International Journal.

Conz, E. and Magnani, G. (2020), "A dynamic perspective on the resilience of firms: a systematic literature review and a framework for future research", European Management Journal, Vol. 38 No. 3, pp. 400-412.

Copeland, S., Comes, T., Bach, S., Nagenborg, M., Schulte, Y. and Doorn, N. (2020), "Measuring social resilience: trade-offs, challenges and opportunities for indicator models in transforming societies", International Journal of Disaster Risk Reduction, Vol. 51, p. 101799.

Cui, P. and Li, D. (2019), "Measuring the disaster resilience of an urban community using ANP-FCE method from the perspective of capitals", Social Science Quarterly, Vol. 100 No. 6, pp. 2059-2077.

Dahles, H. and Susilowati, T.P. (2015), "Business resilience in times of growth and crisis", Annals of Tourism Research, Vol. 51, pp. 34-50.

Danes, S.M., Stafford, K., Haynes, G. and Amarapurkar, S.S. (2009), "Family capital of family firms: bridging human, social, and financial capital", Family Business Review, Vol. 22 No. 3, pp. 199-215.

Datta, P. (2017), "Supply network resilience: a systematic literature review and future research", The International Journal of Logistics Management.

Demmer, W.A., Vickery, S.K. and Calantone, R. (2011), "Engendering resilience in small-and mediumsized enterprises (SMEs): a case study of Demmer Corporation", International Journal of Production Research, Vol. 49 No. 18, pp. 5395-5413.

Denyer, D. (2017), "Organisational Resilience: a summary of academic evidence, business insights and new thinking", BSI and Cranfield School of Management, pp. 8-25.

DesJardine, M., Bansal, P. and Yang, Y. (2019), "Bouncing back: building resilience through social and environmental practices in the context of the 2008 global financial crisis", Journal of Management, Vol. 45 No. 4, pp. 1434-1460.

Dharmasena, M.G.I., Toledano, M. and Weaver, C.K. (2020), “The role of public relations in building community resilience to natural disasters: perspectives from Sri Lanka and New Zealand", Journal of Communication Management.

Duchek, S., Raetze, S. and Scheuch, I. (2020), "The role of diversity in organisational resilience: a theoretical framework", Business Research, Vol. 13 No. 2, pp. 387-423.

Dumitraşcu, V. and Dumitraşcu, R.A. (2016), "The use of fuzzy sets and elements of the information theory for assessing the resilience level of business organizations", Quality-Access to Success, Vol. 17.

Edgeman, R. and Williams, J.A. (2014), "Enterprise self-assessment analytics for sustainability, resilience and robustness", The TQM Journal.

Fallah-Aliabadi, S., Ostadtaghizadeh, A., Ardalan, A., Fatemi, F., Khazai, B. and Mirjalili, M.R. (2020), "Towards developing a model for the evaluation of hospital disaster resilience: a systematic review", BMC Health Services Research, Vol. 20 No. 1, p. 64. 
Fan, C., Zhang, C., Yahja, A. and Mostafavi, A. (2021), "Disaster City Digital Twin: a vision for integrating artificial and human intelligence for disaster management", International Journal of Information Management, Vol. 56, p. 102049.

Feng, S., Hossain, L. and Paton, D. (2018), "Harnessing informal education for community resilience", Disaster Prevention and Management.

Finucane, M.L., Blum, M.J., Ramchand, R., Parker, A.M., Nataraj, S., Clancy, N., Cecchine, G., Chandra, A., Slack, T., Hobor, G. and Ferreira, R.J. (2020), "Advancing community resilience research and practice: moving from 'me' to 'we' to '3D'", Journal of Risk Research, Vol. 23 No. 1, pp. 1-10.

Gilly, J.P., Kechidi, M. and Talbot, D. (2014), "Resilience of organisations and territories: the role of pivot firms", European Management Journal, Vol. 32 No. 4, pp. 596-602.

Giroux, J. and Prior, T. (2012), Factsheet Expressions of Resilience: from "Bounce Back" to Adaptation, ETH Zurich.

Hamel, G. and Valikangas, L. (2003), In Search of Resilience.

Heinimann, H.R. and Hatfield, K. (2017), "Infrastructure resilience assessment, management and governance-state and perspectives", Resilience and Risk, Springer, Dordrecht, pp. 147-187.

Helbing, D. (2013), "Globally networked risks and how to respond", Nature, Vol. 497 No. 7447, pp. 51-59.

Herbane, B. (2015), "Threat orientation in small and medium-sized enterprises: understanding differences toward acute interruptions", Disaster Prevention and Management.

Hollnagel, E. (2014), "Resilience engineering and the built environment", Building Research and Information, Vol. 42 No. 2, pp. 221-228.

Ismail, H.S., Poolton, J. and Sharifi, H. (2011), "The role of agile strategic capabilities in achieving resilience in manufacturing-based small companies", International Journal of Production Research, Vol. 49 No. 18, pp. 5469-5487.

Jaaron, A. and Backhouse, C.J. (2014), "Building antifragility in service organisations: going beyond resilience", International Journal of Services and Operations Management, Vol. 19 No. 4, pp. 491-513.

Jan, C.Y. (2013), "Strategy of disaster reduction in Taiwan: decision-making, community, collaborative accountability, and information", Fudan Public Administration Revolution, Vol. 10, pp. 76-79.

Jurgens, M. and Helsloot, I. (2018), "The effect of social media on the dynamics of (self) resilience during disasters: a literature review", Journal of Contingencies and Crisis Management, Vol. 26 No. 1, pp. 79-88.

Kachali, H., Storsj6, I., Haavisto, I. and Kovacs, G. (2018), "Inter-sectoral preparedness and mitigation for networked risks and cascading effects", International Journal of Disaster Risk Reduction, Vol. 30, pp. 281-291.

Kamalahmadi, M. and Parast, M.M. (2016), "A review of the literature on the principles of enterprise and supply chain resilience: major findings and directions for future research", International Journal of Production Economics, Vol. 171, pp. 116-133.

Karman, A. (2020), "Flexibility, coping capacity and resilience of organisations: between synergy and support", Journal of Organizational Change Management.

Khazai, B., Anhorn, J. and Burton, C.G. (2018), "Resilience performance scorecard: measuring urban disaster resilience at multiple levels of geography with case study application to Lalitpur, Nepal", International Journal of Disaster Risk Reduction, Vol. 31, pp. 604-616.

Kong, T.M., de Villiers, A.C., Ntloana, M.B., Pollard, S. and Vogel, C. (2020), "Implementing capacity development for disaster risk reduction as a social learning system", International Journal of Disaster Risk Reduction, Vol. 50, p. 101740.

Lavell, A., Oppenheimer, M., Diop, C., Hess, J., Lempert, R., Li, J., Muir-Wood, R., Myeong, S., Moser, S., Takeuchi, K. and Cardona, O.D. (2012), "Climate change: new dimensions in disaster risk, exposure, vulnerability, and resilience", in Managing the Risks of Extreme Events and Disasters 
to Advance Climate Change Adaptation: Special Report of the Intergovernmental Panel on Climate Change, Cambridge University Press, pp. 25-64.

Lee, A.V., Vargo, J. and Seville, E. (2013), 'Developing a tool to measure and compare organisations' resilience", Natural Hazards Review, Vol. 14 No. 1, pp. 29-41.

Lengnick-Hall, C.A. and Beck, T.E. (2005), "Adaptive fit versus robust transformation: how organizations respond to environmental change", Journal of Management, Vol. 31 No. 5, pp. 738-757.

Lengnick-Hall, C.A., Beck, T.E. and Lengnick-Hall, M.L. (2011), "Developing a capacity for organisational resilience through strategic human resource management", Human Resource Management Review, Vol. 21 No. 3, pp. 243-255.

Lin, Y., Kelemen, M. and Tresidder, R. (2018), "Post-disaster tourism: building resilience through community-led approaches in the aftermath of the 2011 disasters in Japan", Journal of Sustainable Tourism, Vol. 26 No. 10, pp. 1766-1783.

Linnenluecke, M.K. (2017), "Resilience in business and management research: a review of influential publications and a research agenda", International Journal of Management Reviews, Vol. 19 No. 1, pp. 4-30.

Linnenluecke, M. and Griffiths, A. (2010), "Beyond adaptation: resilience for business in light of climate change and weather extremes", Business and Society, Vol. 49 No. 3, pp. 477-511.

Linnenluecke, M.K., Griffiths, A. and Winn, M. (2012), "Extreme weather events and the critical importance of anticipatory adaptation and organisational resilience in responding to impacts", Business Strategy and the Environment, Vol. 21 No. 1, pp. 17-32.

Ma, Z., Xiao, L. and Yin, J. (2018), “Toward a dynamic model of organisational resilience”, Nankai Business Review International.

McGuinness, G., Hogan, T. and Powell, R. (2018), "European trade credit use and SME survival", Journal of Corporate Finance, Vol. 49, pp. 81-103.

Medel, K., Kousar, R. and Masood, T. (2020), "A collaboration-resilience framework for disaster management supply networks: a case study of the Philippines", Journal of Humanitarian Logistics and Supply Chain Management.

Moher, D., Liberati, A., Tetzlaff, J. and Altman, D.G. and The PRISMA Group (2009), "Preferred reporting items for systematic reviews and meta-analyses: the PRISMA statement", Annals of Internal Medicine, Vol. 151 No. 4, pp. 264-269.

Moore, S.B. and Manring, S.L. (2009), "Strategy development in small and medium sized enterprises for sustainability and increased value creation", Journal of Cleaner Production, Vol. 17 No. 2, pp. 276-282.

Ostadtaghizadeh, A., Aliabadi, S.F., Ardalan, A., Fatemi, F., Khazaei, B. and Mirjalili, M.R. (2019), Towards Developing a Model for the Evaluation of Hospital Disaster Resilience: A Systematic Review.

Pal, R., Torstensson, H. and Mattila, H. (2014), "Antecedents of organisational resilience in economic crises-an empirical study of Swedish textile and clothing SMEs", International Journal of Production Economics, Vol. 147, pp. 410-428.

Parsons, M., Glavac, S., Hastings, P., Marshall, G., McGregor, J., McNeill, J., Morley, P., Reeve, I. and Stayner, R. (2016), "Top-down assessment of disaster resilience: a conceptual framework using coping and adaptive capacities", International Journal of Disaster Risk Reduction, Vol. 19, pp. 1-11.

Petrudi, S.H.H., Tavana, M. and Abdi, M. (2020), "A comprehensive framework for analysing challenges in humanitarian supply chain management: a case study of the Iranian Red Crescent Society", International Journal of Disaster Risk Reduction, Vol. 42, p. 101340.

Pollock, M.J., Wennerstrom, A., True, G., Everett, A., Sugarman, O., Haywood, C., Johnson, A., Meyers, D., Sato, J., Wells, K.B. and Arevian, A.C. (2019), "Preparedness and community resilience in 
disaster-prone areas: cross-sectoral collaborations in South Louisiana, 2018", American Journal of Public Health, Vol. 109, pp. S309-S315.

Prayag, G. (2018), "Symbiotic relationship or not? Understanding resilience and crisis management in tourism", Tourism Management Perspectives, Vol. 25, pp. 133-135.

Râsânen, A., Lein, H., Bird, D. and Setten, G. (2020), "Conceptualising community in disaster risk management", International Journal of Disaster Risk Reduction, Vol. 45, p. 101485.

Ramezani, J. and Camarinha-Matos, L.M. (2020), "Approaches for resilience and antifragility in collaborative business ecosystems", Technological Forecasting and Social Change, Vol. 151, p. 119846.

Reinmoeller, P. and Van Baardwijk, N. (2005), "The link between diversity and resilience", MIT Sloan Management Review, Vol. 46 No. 4, p. 61.

Richtner, A. and L6fsten, H. (2014), "Managing in turbulence: how the capacity for resilience influences creativity", $R \& D$ Management, Vol. 44 No. 2, pp. 137-151.

Rodríguez-Sanchez, A., Guinot, J., Chiva, R. and Lopez-Cabrales, A. (2019), "How to emerge stronger: antecedents and consequences of organizational resilience", Journal of Management and Organization, pp. 1-18.

Sabahi, S. and Parast, M.M. (2020), "Firm innovation and supply chain resilience: a dynamic capability perspective", International Journal of Logistics Research and Applications, Vol. 23 No. 3, pp. 254-269.

Saurin, T.A., Wachs, P., Righi, A.W. and Henriqson, E. (2014), "The design of scenario-based training from the resilience engineering perspective: a study with grid electricians", Accident Analysis and Prevention, Vol. 68, pp. 30-41.

Simone, C., Iandolo, F., Fulco, I. and Loia, F. (2021), "Rome was not built in a day. Resilience and the eternal city: insights for urban management", Cities, Vol. 110, p. 103070.

Smallbone, D., Deakins, D., Battisti, M. and Kitching, J. (2012), "Small business responses to a major economic downturn: empirical perspectives from New Zealand and the United Kingdom", International Small Business Journal, Vol. 30 No. 7, pp. 754-777.

Son, C., Sasangohar, F., Neville, T., Peres, S.C. and Moon, J. (2020), "Investigating resilience in emergency management: an integrative review of literature", Applied Ergonomics, Vol. 87, p. 103114.

Starr, R., Newfrock, J. and Delurey, M. (2003), "Enterprise resilience: managing risk in the networked economy", Strategy and Business, Vol. 30, pp. 70-79.

$\mathrm{Su}$, H.C. and Linderman, K. (2016), "An empirical investigation in sustaining high-quality performance”, Decision Sciences, Vol. 47 No. 5, pp. 787-819.

Sutcliffe, K.M. and Vogus, T. (2003), "Organising for resilience", Positive Organisational Scholarship: Foundations of a New Discipline, pp. 94-110.

Takasaki, Y. (2016), "Learning from disaster: community-based marine protected areas in Fiji", Environment and Development Economics, Vol. 21 No. 1, pp. 53-77.

Tracey, N. and French, E. (2017), "Influence your firm's resilience through its reputation: results won't happen overnight but they will happen!", Corporate Reputation Review, Vol. 20 No. 1, pp. 57-75.

Wedawatta, G. and Ingirige, B. (2012), "Resilience and adaptation of small and medium-sized enterprises to flood risk", Disaster Prevention and Management: An International Journal.

Weick, K.E. and Sutcliffe, K.M. (2015), Managing the Unexpected: Sustained Performance in a Complex World, John Wiley \& Sons.

Wildavsky, A. (1991), Searching for Safety, Transaction, New Brunswick, NJ.

Williams, T.A., Gruber, D.A., Sutcliffe, K.M., Shepherd, D.A. and Zhao, E.Y. (2017), "Organisational response to adversity: fusing crisis management and resilience research streams", Academy of Management Annals, Vol. 11 No. 2, pp. 733-769. 


\section{Further reading}

Lengnick-Hall, C.A. and Beck, T.E. (2009), Resilience Capacity and Strategic Agility: Prerequisites for Thriving in a Dynamic Environment, UTSA, College of Business, San Antonio, TX, pp. 39-69.

Penades, M.C., Nuñez, A.G. and Canos, J.H. (2017), "From planning to resilience: the role (and value) of the emergency plan", Technological Forecasting and Social Change, Vol. 121, pp. 17-30.

Simmie, J. and Martin, R. (2010), "The economic resilience of regions: towards an evolutionary approach", Cambridge Journal of Regions, Economy and Society, Vol. 3 No. 1, pp. 27-43.

Thayaparan, M., Siriwardena, M., Malalgoda, C.I., Amaratunga, D., Lill, I. and Kaklauskas, A. (2015), "Enhancing post-disaster reconstruction capacity through lifelong learning in higher education", Disaster Prevention and Management.

Weick, K.E. (1993), "The collapse of sensemaking in organisations: the Mann Gulch disaster", Administrative Science Quarterly, pp. 628-652.

Weiner, J.M. and Walsh, J.J. Jr (2015), "Community resilience assessment and literature analysis", Journal of Business Continuity and Emergency Planning, Vol. 9 No. 1, pp. 84-93.

Zucchella, A. and Magnani, G. (2016), International Entrepreneurship: Theoretical Foundations and Practices, Springer. 